\title{
Marginal and internal fit of full ceramic crowns milled using CADCAM systems on cadaver full arch scans
}

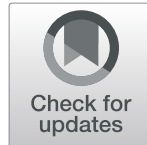

János Vág ${ }^{1 *}$ D,$Z$ Zsolt Nagy ${ }^{1}$, Christopher Bocklet ${ }^{2}$, Tamás Kiss ${ }^{3}$, Ákos Nagy $^{4}$, Botond Simon ${ }^{1}$, Ákos Mikolicz ${ }^{1}$ and Walter Renne ${ }^{5}$

\begin{abstract}
Background: Chairside systems are becoming more popular for fabricating full-ceramic single restorations, but there is very little knowledge about the effect of the entire workflow process on restoration fit. Therefore, this study aimed to compare the absolute marginal discrepancy (AMD) and the full internal fit (FULL) of all-ceramic crowns made by two chairside systems, Planmeca FIT and CEREC, with detailed and standard mill settings.

Methods: One upper molar was prepared for an all-ceramic crown in human cadaver maxilla. Full-arch scans were made by Emerald or Omnicam four times each. Twenty-four e.max crowns were designed and milled by the Planmill 30s or 40s or CEREC MCXL mills with either detailed or standard settings. The cadaver tooth was extracted, and each crown was fixed on it and scanned by a high-resolution microCT scanner. The AMD and FULL were measured digitally in mesio-distal and bucco-lingual 2D slices. The actual and predicted times of the milling were also registered.

Results: No differences were observed between detailed or standard settings in either system. The AMD was significantly higher with CEREC $(132 \pm 12 \mu \mathrm{m})$ than with either Planmill 30s $(71 \pm 6.9 \mu \mathrm{m})$ or $40 \mathrm{~s}(78 \pm 7.7 \mu \mathrm{m})$. In standard mode, the FULL was significantly higher with CEREC $(224 \pm 9.6 \mu \mathrm{m})$ than with either Planmill $30 \mathrm{~s}(169 \pm$ $8.1 \mu \mathrm{m})$ or $40 \mathrm{~s}(178 \pm 8.5 \mu \mathrm{m})$. There was no difference between actual and predicted time with the two Planmeca models, but with CEREC, the actual time was significantly higher than the predicted time. The 30s had significantly higher actual and predicted times compared to all other models. Across all models, the average milling time was 7.2 min less in standard mode than in detailed mode.

Conclusions: All fit parameters were in an acceptable range. No differences in fit between Planmeca models suggest no effect of spindle number on accuracy. The detailed setting has no improvement in the marginal or internal fit of the restoration, yet it increases milling time.
\end{abstract}

Keywords: Digital impression, Intraoral scan, Accuracy, Marginal gap, Marginal fit, Chairside CADCAM, Full-ceramic crown

\footnotetext{
* Correspondence: drvagjanos@gmail.com

'Department of Conservative Dentistry, Semmelweis University, Szentkirályi utca 47, Budapest H-1088, Hungary

Full list of author information is available at the end of the article
}

C C The Author(s). 2020 Open Access This article is licensed under a Creative Commons Attribution 4.0 International License, which permits use, sharing, adaptation, distribution and reproduction in any medium or format, as long as you give appropriate credit to the original author(s) and the source, provide a link to the Creative Commons licence, and indicate if changes were made. The images or other third party material in this article are included in the article's Creative Commons. licence, unless indicated otherwise in a credit line to the material. If material is not included in the article's Creative Commons licence and your intended use is not permitted by statutory regulation or exceeds the permitted use, you will need to obtain permission directly from the copyright holder. To view a copy of this licence, visit http://creativecommons.org/licenses/by/4.0/ The Creative Commons Public Domain Dedication waiver (http://creativecommons.org/publicdomain/zero/1.0/) applies to the data made available in this article, unless otherwise stated in a credit line to the data. 


\section{Background}

In modern dentistry, the 3D scanning and modeling capabilities allow design work to be done digitally chairside instead of in a traditional laboratory setting. The combination of digital design and machine manufacturing techniques is termed computer-aided design/computeraided manufacturing (CADCAM). Current literature has extensively investigated the fit of conventionally fabricated fixed restorations, both at the restoration margin and internal surface [1-5]. Because of the ease of measuring, the marginal fit is often emphasized above internal fit in the literature. For example, studies quantify the marginal fit of non-CADCAM restorations to range between $9 \mu \mathrm{m}$ and $112 \mu \mathrm{m}$ depending on the restoration type and material. This may be strongly influenced by the measurement method, restoration cementation, and the preparation design [1-5].

Although digital dentistry applications afford significant advantages to patients (such as crown preparation and delivery in one appointment and increased patient comfort with digital impressions), many clinicians are hesitant to adopt this new technology chairside. Previously, one main concern was the large marginal gap that was found on restorations milled by early generations of the CEREC systems [6, 7]. Practitioners may believe these outdated data still hold even with new digital CADCAM systems. Many studies agree that the fit of CADCAM restorations is comparable to non-CADCAM restorations, if not better $[3-5,8,9]$. According to recent meta-analyses $[10,11]$, single CADCAM restorations made by intraoral scanners (IOS) have similar marginal gaps as traditional elastomer impression methods.

Many factors influence the full digital approach, such as IOS brand, technology, scanning pattern [12-15], milling type and setting [16], preparation design and quality $[17,18]$, cement gap spacing [19], and software version [20]. There are chairside systems currently in use by practitioners but for which there exists very little published literature $[16,17,21]$. Therefore, there is a consistent need in the literature to evaluate the accuracy of dental scanning and milling systems with each successive product iteration.

Of important note is the limited availability of literature on digital scanning systems using true human tissue. Many studies compare scanners (and subsequently milled restorations) using typodont crown preparations $[16,19,22]$. However, because of the significant differences in material properties (including reflective index, hardness, and translucency), a typodont-based methodology likely diminishes the clinical significance of the findings [23, 24]. Additionally, a standalone typodont lack of neighboring teeth; therefore, the access of the proximal surfaces is not limited by the scanner head compared to the dentate arch [25].
Therefore, this study aimed to compare the accuracy of all-ceramic crowns fabricated by three IOS systems and their corresponding mills (CEREC Omnicam with MCXL mill; Planmeca Emerald with 40s and 30s mills). In order to mimic the clinical situation, a dentulous cadaver arch was used, and the scan was initiated at the contralateral side. The null hypothesis is that there is no difference in the marginal gap or the internal gap between crowns fabricated from CEREC Omnicam and MCXL and Planmeca Emerald and 40s and 30s systems in either detailed or standard mode.

\section{Methods}

\section{Preparation of the samples}

For comparison of scans on biological tissues, a human cadaver maxilla specimen was resected. The specimen contained hard and soft tissue and was preserved using methods previously described in detail [23]. The cadaver tissue used in this study was obtained from Anatomy Gifts Registry (AGR) is owned and operated by the Anatomic Gift Foundation, Inc. (Hanover, MD, U.S.). It is an independent, non-profit, anatomic donation organization that supports advancements in scientific research and medical education. All cadavers are donated to the AGR are obtained following written informed consent from the individual (1st person or willed authorization) or from a loved one (3rd person authorization). This study was deemed exempt from review by the Institutional Review Board for Human Research at the Medical University of South Carolina (Pro 77,251). According to this, no informed consent was necessary to use cadaver tissue.

An all-ceramic crown preparation by chamfer margin was performed on tooth 3 . The preparation specifications of Rosensteil [26] and Shillingburg [27] were followed. A smooth, $1 \mathrm{~mm}$ modified shoulder finish line avoiding spikes and lips that follows the rise and fall of the gingiva was prepared using a diamond bur (8847KR016, Brasseler, Savannah, GA, U.S.). The abutment was prepared rounded, and smoothed surfaces converged coronals by 10 degrees angle, with functional cusp bevel, 1.5 to $2 \mathrm{~mm}$ of occlusal reduction, 1 to $1.5 \mathrm{~mm}$ of axial reduction. Four full-arch scans were taken digitally using Planmeca Emerald (PE; Planmeca U.S., Roselle, IL) and four by CEREC Omnicam (CO; Dentsply Sirona, York, PA) IOS systems. All scans began contralaterally at tooth 15 and finished at tooth 3 [28]. Careful thought went into selecting an individual to scan with each scanner. For CEREC we had a CEREC trainer with 10 years of experience on CEREC, and for Emerald we had an Emerald trainer with also 10 years of experience. This was to remove intrinsic biases of having one person scan on both systems as invariably, users have a favorite system. By bringing in trainers for the systems to scan, we represent 
each scanner to the best ability. The scan patterns recommended by the manufacturers were applied. One master scan was obtained using the ATOS Capsule scanner (GOM, Braunschweig, Germany), which has demonstrated trueness of $3 \mu \mathrm{m}$ and precision of $2 \mu \mathrm{m}[29,30]$. Following scanning, tooth 3 was extracted using forceps extraction and stored in sterile saline away from light or heat.

\section{Restoration design}

In order to standardize the size and shape of the milled restorations, a 3D-printed wax-up model of the maxilla specimen was created. The team used the master ATOS Capsule scan and digitally waxed tooth 3 to full contour using 3Shape laboratory software (3Shape Dental System 2017, 3Shape A/S, Copenhagen, Denmark). The waxed design was appended to the digital maxilla model, and the combined model was 3D-printed in plastic resin (Planmeca CREO C5 at $50 \mu \mathrm{m}$ resolution, Planmeca Model Resin). This replica model was scanned using the Emerald and Omnicam scanners and used by the software as a template for the external surface of the crown designs. Therefore, across both systems, all crowns milled were standardized in external dimensions.

Crown designs were prepared on each IOS system's respective software (Romexis, Planmeca, v5.2; CEREC software, Dentsply Sirona, v4.5). One digital crown design was designed for each scan of the maxilla.

\section{Milling}

Three milling machines with three axes were used. The CEREC MCXL and Planmeca 40s have two spindles moving simultaneously, the Planmeca 30s has one spindle, and in both the MCXL and 30s, the milling blocks can rotate.

Each digital crown design was milled twice with each mill: one crown at the system's slower setting mode ("detailed," Planmeca; "fine," CEREC) and the other at the system's faster setting mode ("standard," Planmeca; "fast," CEREC). Planmill models use different burs (tools) for milling the internal surface of the restoration, depending on the setting. For the standard setting, an ellipsoidal bur with parallel axial walls and a flat end is used with a diameter of $1.6 \mathrm{~mm}$ (PlanMill Two Striper ${ }^{\circ}$ Milling Diamond Burs Premier Dental Products, U.S.). In contrast, for a detailed setting, a conical bur is used with tapered axial walls. It has a rounded end and a smaller diameter at the tip $(1.1 \mathrm{~mm})$. CEREC uses the same tools for the fast and fine settings but producing more rough surfaces in case of a fast setting, according to the manufacturer. The intaglio was milled using the $12 \mathrm{~S}$ Step Bur with a $1.3 \mathrm{~mm}$ diameter (Dentsply Sirona, Germany).
All crowns were milled of lithium disilicate ceramic blocks (IPS e.max CAD, size C14, color HT B2, Ivoclar Vivadent, Schaan, Lichtenstein) using new diamond burs and clean machines. Only one mill for each scan-modemodel (MCXL, 40S, 30S) was used for crown fabrication, for a total of 24 milled crowns.

Margin width was set at $250 \mu \mathrm{m}$ ("margin ramp," Planmeca; "margin thickness," CEREC), and cement gap at $70 \mu \mathrm{m}$ ("space thickness," Planmeca; "spacer," CEREC). All other parameters were accepted at default e.max parameters for each software. Sprue location was set slightly buccal of MB cusp and otherwise accepted at the software's proposed location (i.e., coronal-apical position). Crowns were centered in milling block for standardization. Mill times were recorded from initiation of motor movement to visual confirmation on the device's screen that milling was complete. All sprues were cut using a fine diamond bur to appropriate crown contour. Crowns were fired in an oven using the firing cycle recommended by the manufacturer (IPS e.max ${ }^{\circ}$ CAD Speed crystallization, Ivoclar Vivadent, Programat CS) without prior application of gloss or stains.

\section{Micro-CT measurements of marginal and internal fit}

Crowns were individually seated on the extracted tooth and tightly fixed by a rubber ring. Each specimen (crown and tooth) was scanned in a SkyScan 1172 micro-CT scanner (SkyScan, Aartselaar, Belgium). Images were acquired using $80 \mathrm{kV}$ maximum accelerating voltage, $310 \mu \mathrm{A}$ current, and $1 \mathrm{~mm}$ Al filter with a pixel size of $8.7 \mu \mathrm{m}$. The specimens were scanned at frames per rotation step of 0.7 $\left(180^{\circ}\right)$. After scanning, the images were reconstructed in software NRecon, which uses an FDK (FeldkampDavis-Kress) algorithm. DataViewer software (SkyScan, Aartselaar, Belgium, v1.5.2) was used to section each scan at the central region in the mesial-distal and buccal-lingual directions (Fig. 1). Because the same tooth was used in each scan, rotating the tooth to the same position allowed all scans to be sectioned in an identical position. The files were saved as .bmp format.

The two sections were imported into ImageJ software (National Institute of Health, Bethesda, Maryland, USA, v1.52a) to make the gap measurements. The marginal and internal fit of the specimens were assessed as recommended by Holmes et al. [31] at various points: absolute marginal discrepancy (AMD), finish line (FL), axial wall (AW), axio-occlusal angle at cusp (CU), and central of occlusal area (CO). The points were measured buccally, lingually, mesially, and distally using both scan sections (Fig. 2). The perimeter between the restoration and tooth was also measured to calculate an average full gap between the 


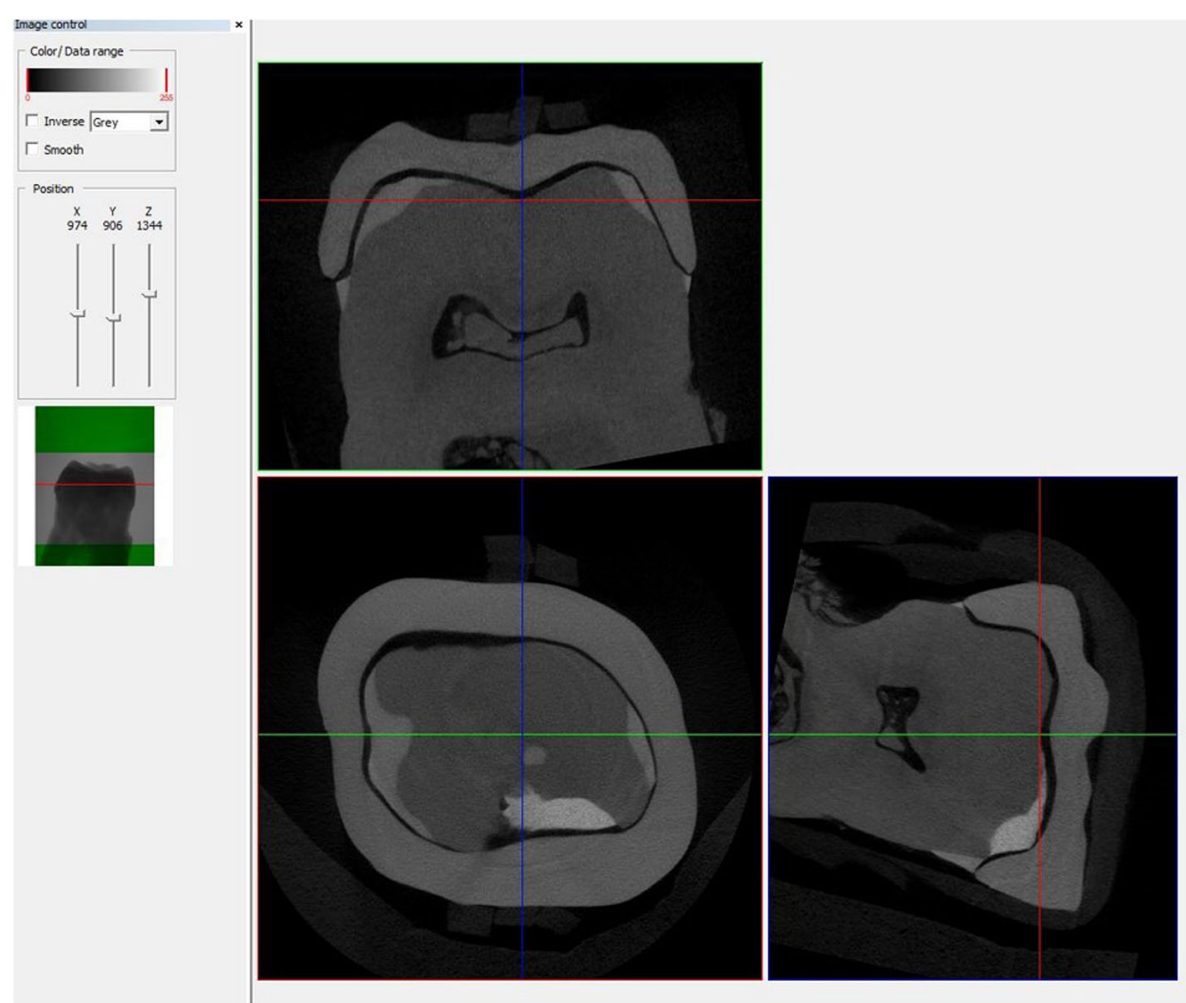

Fig. 1 The section made in DataViewer in the identical position

two surfaces (Fig. 2). The measurements were repeated five times by five observers without knowing the group specification of the specimen (blinded analysis). They were not involved in either in the fabrication process (scanning or milling) or in the microCT measurement. Similarly, the microCT measurement was done by two investigators not involved in other processes, and the sectioning of the microCT scan in
DataViewer was done by a single observer who was not involved in other processes either.

\section{Statistical analysis}

The 100 data points per specimen were exported to MS Excel for organization and then exported into SPSS 25 (IBM SPSS Statistics for Windows, Version 24.0. IBM Corp., Armonk, NY., U.S.) for further statistical analysis.

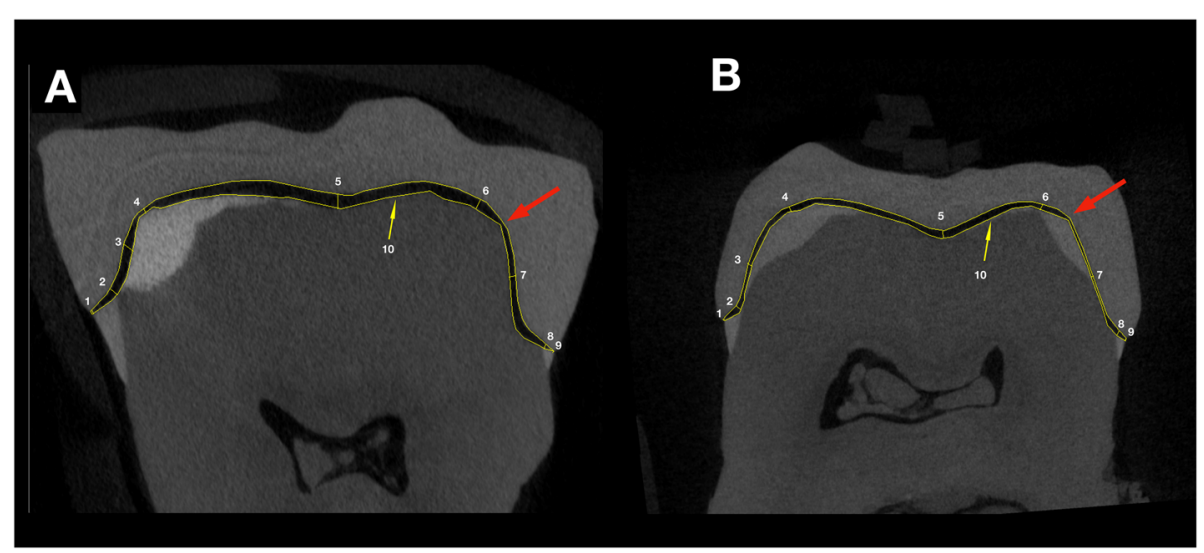

Fig. 2 Sites of measurement on the mesio-distal section (a) and on the oro-vestibular section (b). The sites are numbered from mesial to distal and from oral to vestibular in the following manner: 1 - absolute marginal discrepancy (AMD), 2 - finish line (FL), 3 - axial wall (AW), 4 - axioocclusal angle at cusp (CU), 5 - central of occlusal area (CO), and similarly 6, 7, 8, 9 on the other side of the tooth. The area selection between restoration and the tooth is indicated by $\mathrm{N}^{\circ} 10$. A big red arrow indicates the possible point of the first contact of the restoration 
Gap data were analyzed with the generalized linear mixed-model approach with gamma distribution and log-link function using restricted maximum likelihood estimation. In the complex design, the site, the mill model, and the mill mode (standard/fast vs. detailed/ fine) were the main fixed factors, with their interactions integrated into the model. The section was included in a second design to test the difference in AMD between sections. The $p$ values were adjusted using the Bonferroni method for pair-wise comparison with an alpha value set at 0.05 . Data in the text and figures are presented as estimated marginal mean \pm standard error.

The inter-rater reliability was evaluated in two ways. The relative reliability was assessed by the intraclass correlation coefficient (ICC) [32]. The absolute agreement form of ICC was utilized as both the trueness and precision of the measurements were considered [33, 34]. ICC values of $<0.40,0.40-0.75$, and $>0.75$ were considered as poor, fair-to-good, and excellent agreement, respectively [35]. The reliability was also assessed by the calculation of the within-subject coefficient of variation [36]. It measures reproducibility by determining the degree of closeness of repeated measurements taken on the same subject by the different observers under the same condition. It gives estimates for the magnitude of the error during distance measurement on the section made by the observer. The coefficient of variation $(\mathrm{CV})$ was calculated from the variance component $(\mathrm{VC})$ of the log-transformed variable using the following formula $C V=100 \times \sqrt{V C}$ [37], with a confidence interval of $95 \%$. CV values of $\leq 10 \%, 10-25 \%$, and $\geq 25 \%$ were considered as good, moderate, and poor reliability, respectively [35].

\section{Results}

Inter-rater reliability and variance components of the measurements

The ICC was 0.88, which suggests excellent agreement between the observers. The reliability of averaged measurement increased to 0.97 . The CV was 21\% [20.822.1\%] for the observer, 9\% [2.8-30.5\%] for the section, and 9\% [3.2-25.2\%] for the scan (no differences between Omnicam and Emerald).

\section{Full gap analysis}

The mill mode did not influence the size of the full gap in either model $(p=0.926$, Table 1$)$. Significantly higher full gap value was observed with CEREC than with Planmeca models in standard/fast mode (Fig. 3), but not in detailed/fine mode (30s vs. CEREC $p=0.239,40$ s vs. CEREC $p=0.206$ ). No differences were observed between 30s and 40s models in either mode (standard $p=$ 0.168 , detailed $p=0.713$ ).
Table 1 Gap measured between crowns and abutment

\begin{tabular}{|c|c|c|c|c|c|}
\hline \multirow[b]{3}{*}{ site } & \multirow[b]{3}{*}{ model } & \multicolumn{4}{|c|}{ universal mode } \\
\hline & & \multicolumn{2}{|c|}{ standard/fast } & \multicolumn{2}{|c|}{ detailed/fine } \\
\hline & & Mean & SE & Mean & SE \\
\hline \multirow[t]{3}{*}{ full } & $30 \mathrm{~s}$ & 169 & 8.1 & 182 & 9.3 \\
\hline & $40 \mathrm{~s}$ & 178 & 8.5 & 180 & 8.6 \\
\hline & CEREC & 224 & 9.6 & 204 & 9.9 \\
\hline \multirow[t]{3}{*}{ AMD } & $30 \mathrm{~s}$ & 66 & 8.5 & 76 & 9.9 \\
\hline & $40 \mathrm{~s}$ & 74 & 9.6 & 83 & 10.7 \\
\hline & CEREC & 133 & 14.6 & 130 & 17.0 \\
\hline \multirow[t]{3}{*}{$\mathrm{FL}$} & $30 \mathrm{~s}$ & 180 & 23.4 & 197 & 25.7 \\
\hline & $40 \mathrm{~s}$ & 194 & 25.3 & 180 & 23.5 \\
\hline & CEREC & 125 & 13.7 & 116 & 15.1 \\
\hline \multirow[t]{3}{*}{ AW } & $30 \mathrm{~s}$ & 112 & 14.6 & 134 & 17.5 \\
\hline & $40 \mathrm{~s}$ & 112 & 14.6 & 142 & 18.5 \\
\hline & CEREC & 120 & 13.1 & 120 & 15.6 \\
\hline \multirow[t]{3}{*}{$\mathrm{CU}$} & $30 \mathrm{~s}$ & 125 & 16.3 & 169 & 22.0 \\
\hline & $40 \mathrm{~s}$ & 152 & 19.8 & 146 & 19.0 \\
\hline & CEREC & 236 & 25.8 & 210 & 27.5 \\
\hline \multirow[t]{3}{*}{$\mathrm{CO}$} & $30 \mathrm{~s}$ & 248 & 33.7 & 302 & 41.0 \\
\hline & $40 \mathrm{~s}$ & 271 & 36.8 & 259 & 35.2 \\
\hline & CEREC & 391 & 44.5 & 320 & 43.7 \\
\hline
\end{tabular}

\section{Gap measurement at various sites}

The three-way interaction of mode ${ }^{*}$ site"model was not significant $(p=0.949)$, as well as the two-way interactions of mode ${ }^{*}$ model $(p=0.154)$ and mode*site $(p=0.685)$. The main effect of mode was not significant $(p=0.423)$. A significant effect was observed for the main effect of the site $(p<0.001)$ and the interaction of model*site $(p<0.001)$. Therefore, further pair-wise comparisons were made between sites and between separate models at various sites.

The gap was significantly higher at $\mathrm{CO}$ than at all other sites $(p<0.001$ for each pair, Fig. 4). No difference was observed between CU and FL $(p=0.468)$. Both were significantly higher than AW and AMD $(p<0.001$ for each pair). The next lower values were at AW, but it was significantly higher than AMD $(p<0.001)$. The order of the gap size was as follows: $\mathrm{CO}>\mathrm{CU}=\mathrm{FL}>\mathrm{AW}>\mathrm{AMD}$.

No differences were observed between the 30s and 40s at any sites (Fig. 5). No differences were observed between Planmeca and CEREC models at the axial wall (AW) and central occlusal fossa (CO). CEREC had a higher value at absolute marginal discrepancy (AMD) and cusps (CU) than Planmeca models. Planmeca models had a higher gap at the finish line (FL) than CEREC.

\section{Differences in AMD between sections}

In the three-way factor analysis (model"mode*section), no interactions were found to be significant, and only 


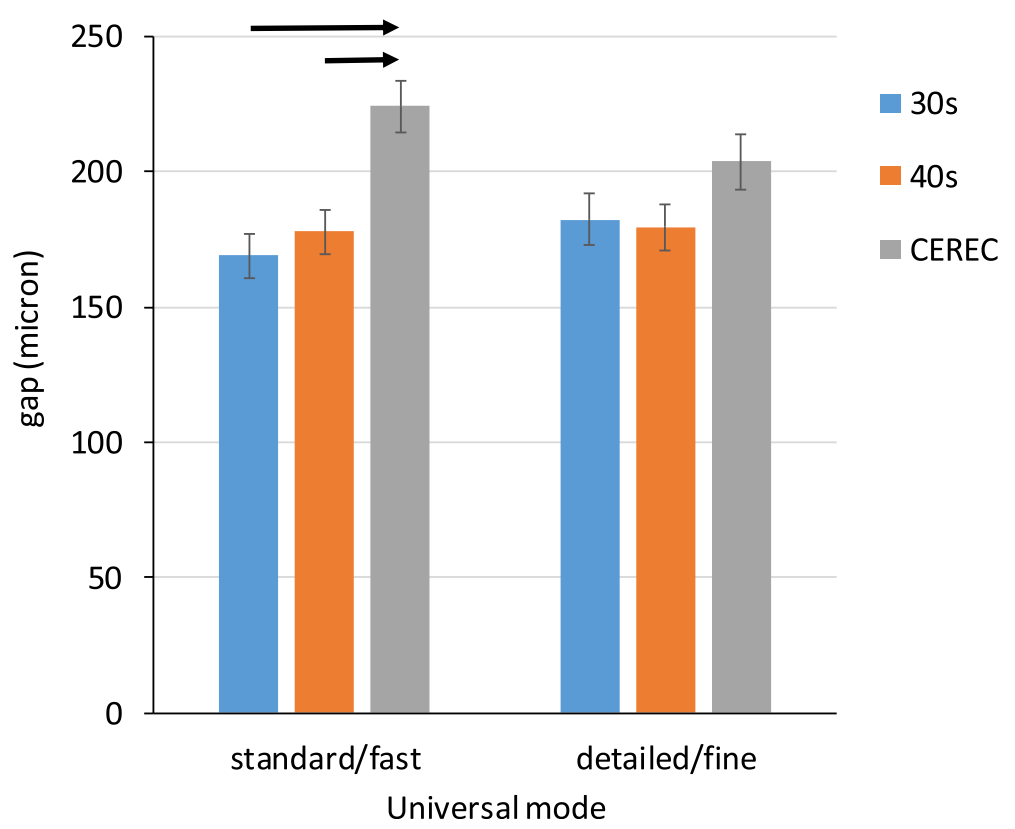

Fig. 3 The full gap between crowns and tooth abutment in microns. Significant differences between models are denoted by black arrows, $p<0.001$

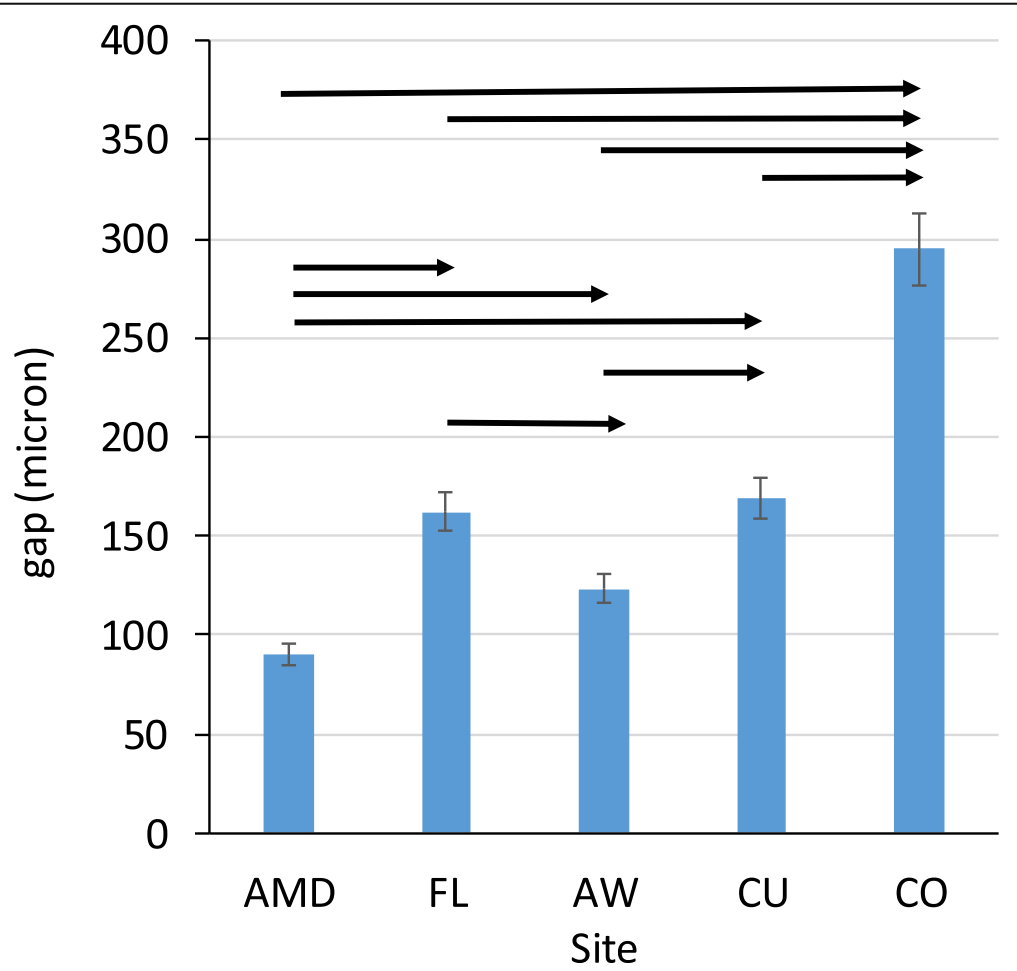

Fig. 4 The gap between crowns and tooth abutment in microns at various sites. Significant differences between sites are denoted by black arrows, $p<0.001$ 


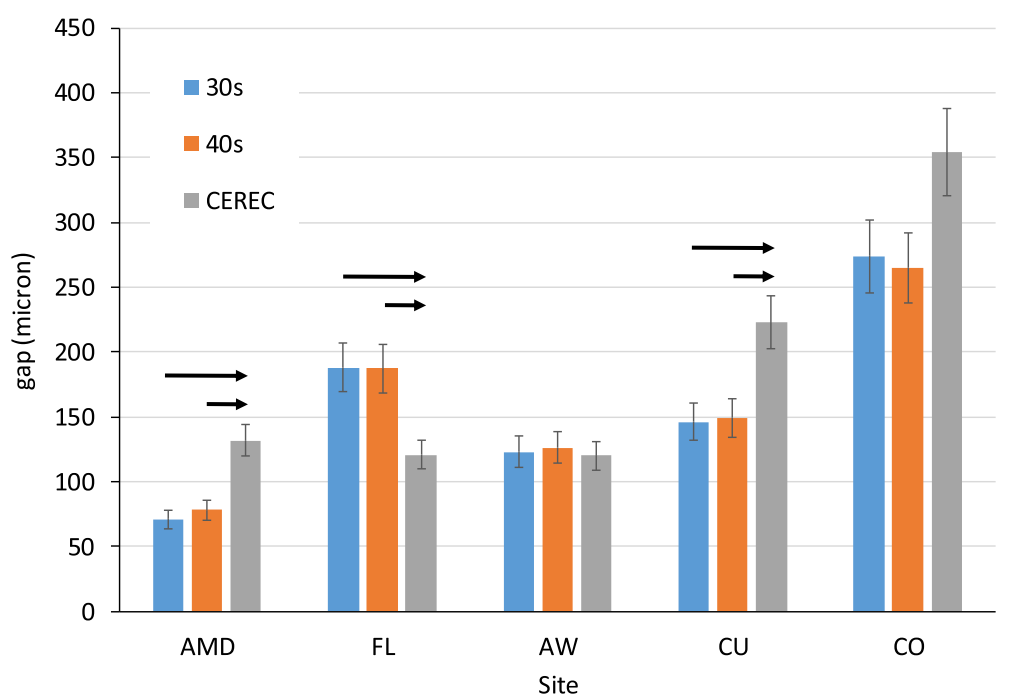

Fig. 5 The gap between crowns and tooth abutment by site and mill system in microns. Significant differences between models by the site are denoted by black arrows, $p<0.01$

the main effect of the section was significant. Thus, regardless of mode and models, the mean AMD on the coronal section $(133 \pm 21 \mu \mathrm{m}$, oral and vestibular measurements) was significantly higher than on the sagittal section $(55 \pm 8.6 \mu \mathrm{m}$, mesial and distal measurements, $p<0.001)$.

\section{Time of milling}

There was no difference between actual and predicted times with the two Planmeca models (30s: $25.2 \pm 2.5 \mathrm{~min}$ vs. $25.2 \pm 2.5 \mathrm{~min}$; $40 \mathrm{~s}: 13.3 \pm 1.4 \mathrm{~min}$ vs. $13.3 \pm 1.4 \mathrm{~min}$ ). In the case of CEREC, the actual time was significantly higher than the predicted time $(13.4 \pm 1.2 \mathrm{~min}$ vs. $10.0 \pm$ $0.9 \mathrm{~min}, p<0.001$ ). The $30 \mathrm{~s}$ had significantly higher actual and predicted time compared to all other models $(p<0.001)$. No significant difference was observed in either actual or predicted time between the $40 \mathrm{~S}$ and CEREC models. In the standard mode, the average milling time was $7.2 \mathrm{~min}$ less than in the detailed mode $(13.3 \pm 0.97 \mathrm{~min}$ vs. $21.8 \pm 1.87 \mathrm{~min}, p<0.001)$ regardless of the model and whether the predicted or actual milling time was considered.

\section{Discussion}

McLean and Fraunhofer, in their landmark in vivo study, quantify a marginal gap of $120 \mu \mathrm{m}$ to be clinically acceptable [1]. However, experienced dentists accepted marginal gaps as great as $455 \mu \mathrm{m}$ while rejecting marginal gaps as small as $117 \mu \mathrm{m}$ [38]. Interestingly, in vitro studies failed to demonstrate a correlation between the marginal gap and leakage [39], even when the gap ranged between 0 and $831 \mu \mathrm{m}$ [40]. However, a strong correlation can be found between gingivitis and marginal discrepancy ranging from 5 to $430 \mu \mathrm{m}$ [41], suggesting that measuring the AMD has a higher relevance than the marginal gap. Restoration longevity is not compromised with marginal gaps up to $120 \mu \mathrm{m}$ for conventional restorations luted by polycarboxylate cement [42] and the marginal gaps above $200 \mu \mathrm{m}$ for CADCAM or heatpressed all-ceramic crowns cemented by adhesive technique [43]. Notwithstanding the lack of direct evidence for a relationship between the marginal gap and restoration longevity, the CADCAM restorations had good clinical success [43-45]. Therefore, some authors [2, 46] question the necessity of the cement film thickness is less than $120 \mu \mathrm{m}$. Similarly, it was found that a significant proportion of marginal gaps were above $150 \mu \mathrm{m}$ in the case of the gold cast [47] despite the well-known high clinical success rate of this restoration $[48,49]$.

Studies comparing the marginal gap of CADCAM ceramic restorations made from digital and conventional impressions $[10,11]$ showed that the mean marginal gap of the digital workflow is in a range between 18 and $128 \mu \mathrm{m}$. Within the included studies, there was a significant variety in preparation design, specimen (an extracted tooth or typodont), milling unit, evaluation method (microCT, silicone replica technique, etc.), and marginal fit measurement (AMD vs. marginal gap). The preparation design (rounded vs. chamfer) does not affect the gap size, according to a meta-analysis [11]. In this study, the AMD measured $71-78 \mu \mathrm{m}$ for Planmeca models and $132 \mu \mathrm{m}$ for CEREC, which appears higher than the range of studies included in the meta-analysis. However, in most studies [5, 16, 17, 50], the marginal gap was measured, defined by Holmes to be the closest measurement from the internal surface of the restoration 
to the wall of the preparation at the margin [31]. Similar to this study, others $[19,22,51]$ measured the absolute marginal discrepancy, which is the distance between the preparation margin and restoration margin. AMD is the summation of the horizontal and vertical marginal discrepancy vectors. This is equivalent to the addition of the marginal gap and overextended margin vectors. This means that AMD is higher than or in an ideal condition perhaps equal to the marginal gap. In studies measuring both parameters, the AMD was found to be $30-118 \%$ greater than the marginal gap [52-54]. Literature regarding marginal fit with chairside systems is available for CEREC, but most of them scanned typodont specimens. The mean marginal gap ranged from 94 to $145 \mu \mathrm{m}$ [16, 17]. These results are comparable to this study's CEREC data, considering the difference between the marginal gap and AMD. However, other studies measured AMD with CEREC systems and obtained lower values, between 53 and $94 \mu \mathrm{m}[19,22,53]$. The lower values of these studies may come from ideal in vitro conditions obtained by scanning a single typodont tooth instead of a full dentate arch dentate. In an in vivo study [55], the mean marginal discrepancy was $149 \mu \mathrm{m}$. This is similar to CEREC results presented here, suggesting that the scanning condition may have a contribution to the error besides the effect of the milling machine and restoration material.

A recent study [56] found that there is a significant difference between the five methods of measuring the marginal fit, and the values obtained by microCT are located in the middle of the five techniques. The results of microCT studies are very similar to those presented here. The mean AMD was 151-161 $\mu$ m with the Omnicam and CEREC inLab milling unit [57] and 145-412 $\mu \mathrm{m}$ after conventional impression [52]. The microCT with high resolution increases the contrast of the margin line of the specimens, which could improve the measurement. In this study, an extremely high resolution $(8.7 \mu \mathrm{m})$ was used, higher than previous studies with 10$19 \mu \mathrm{m}$ resolution [52, 57-59]. The high resolution could contribute to the significant findings in our study despite the low sample number. Groten et al. [60] determined the optimal amount of measurement sites for getting a consistent AMD value in the case of microscopic observation. Their recommendation, making 50 measurements of each sample, became a standard for evaluating AMD by using a microscope [5]. The microscopic evaluation inherently involves projection error due to the frontal view contrary to the sectional view used in microCT. Furthermore, the standard selection of measurement points around the multiple replicas is challenging. In our study, the same abutment was used for each crown, and standardized positions were used for sectioning. The common problem in both methods is that the selection of the starting point and endpoint of the distance measurements is somewhat subjective. In our study, five observers made repetitive measurements in the same section to overcome this type of error. The magnitude of the variation between observers indicated a significant contribution of the distance measurement to the overall error. The involvement of multiple observers allows controlling this error in the statistical model. The whole coefficient of variation in AMD measurement was between 22 and $26 \%$ in our study, which was similar to the $\mathrm{CV}$ in recent microCT studies [52, $57-59,61]$. In conclusion, these results highlight the importance of involving multiple observers in the analyses and indicate the high accuracy of the microCT method.

Manual adjustment or discarding of restorations after visual inspection could greatly decrease the marginal gap and AMD [57], but this technique was not applied in this study contrary to other studies $[4,8,55,57,62,63]$.

Overall, the greatest difference, which distinguishes this experimental design from all others, is the scan of a dentate human maxilla compared to a standalone typodont made of plastic. Typodont abutments are often more easily accessible, especially at the approximal surfaces, for scanning than abutments in a dentate arch [25]. This phenomenon may contribute to the in vivolike AMD values, especially with the CEREC system. Interestingly, the AMD was consistently smaller in the mesiodistal than in the buccolingual section. The variance component analysis revealed that the variance between scans had little contribution to the overall error. Furthermore, no difference in this variance component was observed between Omnicam and Emerald. Therefore, the difference between sections and systems may relate to some milling discrepancy instead of the scanning differences, but the answer to this question requires further studies.

The mean full internal gap was between 169 and $182 \mu \mathrm{m}$ for Planmeca systems and higher for CEREC at 204-224 $\mu \mathrm{m}$. The lowest value in the internal surface was at the axial walls and the highest at the occlusal walls. This is similar to other studies, regardless of conventional $[4,64,65]$, or digital impression was used $[16,59$, 66]. Milling inaccuracies might predominantly occur on the occlusal surface of the CADCAM restorations because of preparation errors and irregularities [16, 59] and digital techniques that may round sharp edges [4]. Axial walls are milled with the side of the instrument bur. In contrast, the inner occlusal surface is milled with the tip of the bur, perhaps exaggerating dimensional discrepancies between instrument size and inner geometry of the restoration.

Mostly, adjustment of the cement spacer could explain the marginal gap being lower than the axial and occlusal gaps. In both conventional casting and CADCAM 
techniques, no space is allocated at the marginal ramp area, and tens to hundreds of microns of space are created at axial and occlusal walls. With the conventional casting technique, the marginal gap was the largest when no spacer was used and dramatically decreased when multiple spacer layers (up to $70 \mu \mathrm{m}$ ) were used [67]. Many studies demonstrated that too thin of a die spacer might inversely increase the gap, likely due to the lack of cement release [68-71]. Similarly, in the case of the CEREC system, increasing the spacer setting from $10 \mu \mathrm{m}$ to $100 \mu \mathrm{m}$ resulted in a lower AMD [19, 20, 72]. One study showed $200 \mu \mathrm{m}$ spacer settings resulted in the lowest marginal gap in e.max crowns made by E4D mill system [73]. In this study, a cement space of $70 \mu \mathrm{m}$ and a margin ramp of $250 \mu \mathrm{m}$ was set for both systems. CEREC manual (Software version 4.6.x) recommends $120 \mu \mathrm{m}$ for the spacer, which is higher than applied in this study. Planmeca FIT CADCAM system's manual recommends $100 \mu \mathrm{m}$ spacer thickness [18]. The spacer setting could compensate for the inaccuracies of the fabrication workflow to minimize the marginal gap. Therefore, a lower spacer setting than factory recommendation may inversely increase the gap, possibly explaining the margin values found to be higher with CEREC than Planmeca.

The internal gap and the cement thickness may influence the retention and fracture resistance of restoration. A very early study [74] found only a very weak correlation between retention of the restoration and zinc phosphate cement thickness in a range of $20-140 \mu \mathrm{m}$. The bond strength of porcelain cemented by resin was not changed by increasing cement thickness from $50 \mu \mathrm{m}$ to $200 \mu \mathrm{m}$ [75]. In another study, increasing the resin cement thickness from $50 \mu \mathrm{m}$ to $100 \mu \mathrm{m}$ decreased the shear bond strength of the disks by 20-43\% [76]. With lithium disilicate ceramic crowns and resin cement, the pulling test resulted in a fracture of the restoration before any adhesive debonding $90 \%$ of the time [77]. It suggests that dual cement is highly retentive, and thus the thickness of the cement within a certain range may be less important. When increasing the cement thickness of resin from 50 to $500 \mu \mathrm{m}$, the fracture resistance of the feldspathic crown decreased significantly $[63,78]$. No significant effect was seen on fracture resistance of IPS e.max CAD milled by CEREC system with cement thickness ranging from 30 to $150 \mu \mathrm{m}$ [79]. In a range of $26-297 \mu \mathrm{m}$, only a slight decrease in fracture strength was observed in glass-ceramic Tabs [80]. According to these data, the internal gap settings of both systems in this study were within an acceptable range.

A difference in accuracy was observed between CEREC and Planmeca systems but not between Planmeca models. Planmill 30s has one 3-axis spindle, and the object can rotate, whereas the 40s and MCXL models have two spindles moving simultaneously in 3 axes. Studies show that the number of axes does not necessarily improve the accuracy of the restoration [54, 59, 81, 82], which is confirmed by the results presented here. The Planmill 30s required more time for milling, likely due to its one spindle. The gap after the whole workflow in this study was likely more dependent on factors described above, such as scanning accuracy of natural hard and soft tissue, finish line distinctness [83], and mill settings. In one study, a significant difference was found between two intraoral scanners in the marginal gap of lithium disilicate crowns despite using the same milling unit, Planmill 40 [21]. They also found a higher gap at buccal and lingual than mesial and distal sites for Planscan, similarly as in this study. As errors could compound through the workflow [84], the importance of researching every step in the workflow must be emphasized.

No difference was observed in gaps between modes of milling (detailed/fine vs. standard/fast). One study demonstrated a significant difference in the marginal gap between detailed and standard mode of Planmill 40 [21], but as discussed previously, a typodont model was used. Research of different CAM strategies (e.g., different bur sizes) of CEREC chairside system shows no statistical differences in the measured gap [16]. E.max crowns fabricated by E4D system had a mean vertical marginal gap of $38 \mu \mathrm{m}$ with ideal preparations and $90 \mu \mathrm{m}$ with poor preparations [18]. This range is similar to the results of this study (85-96 $\mu \mathrm{m}$ for Planmeca models) when taking into account the estimated differences between AMD and marginal gap. It is possible that the lack of difference in accuracy between modes in this study may be a result of continuous software development and the ideal tooth preparation, which could avoid under- or overmilling the internal surface by a larger bur. In this experiment, all crowns were fabricated on the same tooth prepared by an experienced dentist. As the milling took longer in detailed/fine mode, it may be of little benefit to using this mode with a well-prepared abutment.

No difference was found between predicted and actual times in either Planmeca models, suggesting a welldeveloped simulation software. However, for CEREC, the times were underestimated by an average of $3 \mathrm{~min}$. The researcher needs to note that software for both systems is continuously developed and upgraded, which may influence the speed, accuracy, and estimated mill time of restorations [20].

\section{Conclusions}

In this study, it was attempted to simulate the workflow of manufacturing a chairside ceramic restoration from the scanning to try in. The mean marginal discrepancy was at a clinically acceptable level for both systems, 
though Planmeca models had significantly better performance. The cheaper and simpler model, the Planmill 30 s, had the same performance as the Planmill 40s, though it had slower processing times. Interestingly, the time-consuming detailed milling setting had no significant improvement to the fit of full-ceramic crowns. It is necessary to further investigate the entire chairside process with different teeth and preparations to scrutinize the benefit of detailed/fine mode.

\section{Abbreviations \\ CADCAM: Computer-aided design/computer-aided manufacturing; IOS: Intraoral scanner; AMD: Absolute marginal discrepancy; FL: Finish line; AW: Axial wall; CU: Axio-occlusal angle at the cusp; CO: Central of occlusal area; FULL: Full internal fit}

\section{Acknowledgments}

The authors wish to thank dental students Borbála Patthy and Gerle Jakab for their assistance in making 2D measurements.

\section{Authors' contributions}

All the authors made substantial contributions to the present study. WR designed the study, performed critical revisions, JV analyzed and interpreted the results and was a major contributor in writing the manuscript, $C B$ designed and milled the restorations, ZN performed the microCT scan, made the digital measurement on $2 \mathrm{D}$ sections, $\mathrm{AM}$ made the digital measurement on $2 \mathrm{D}$ sections, $\mathrm{BS}$ made the digital measurement on $2 \mathrm{D}$ sections, $\mathrm{AN}$ converted $3 \mathrm{D}$ data to $2 \mathrm{D}$ by sectioning, TK technically supervised and performed the microCT scan and reconstructed the 3D data. The authors read and approved the final manuscript.

\section{Funding}

The study was supported by the following fundings. The Hungarian National Research, Development, and Innovation Office (KFI_16-1-2017-0409) supplied the necessary cost of the consumable (i.e., ceramic blocks, burs etc.). The Hungarian Human Resources Development Operational Program (EFOP-3.6.216-2017-00006) granted the availability of the microCT core facility. NRDI Found (2019-2.1.11-TÉT-2019-00048) supported the mobility of the staff for cooperation between the four Academic Research Center.

\section{Availability of data and materials}

The datasets used and/or analyzed during the current study are available from the corresponding author upon reasonable request.

\section{Ethics approval and consent to participate}

The cadaver tissue used in this study was obtained from Anatomy Gifts Registry (AGR) is owned and operated by the Anatomic Gift Foundation, Inc. (7522 Connelley Drive Suite M, Hanover, MD 21076). It is an independent, non-profit, anatomic donation organization that supports advancements in scientific research and medical education. All cadavers are donated to the AGR are obtained following written informed consent from the individual (1st person or willed authorization) or from a loved one (3rd person authorization). This study was deemed exempt from review by the Institutional Review Board for Human Research at the Medical University of South Carolina (Pro 77251). According to this, no informed consent was necessary to use cadaver tissue.

\section{Consent for publication}

Not applicable.

\section{Competing interests}

Walter Renne is a key opinion leader of Planmeca. The authors declare that they have no other competing interests.

\section{Author details}

'Department of Conservative Dentistry, Semmelweis University, Szentkirályi utca 47, Budapest H-1088, Hungary. ${ }^{2}$ College of Dental Medicine, Medical University of South Carolina, Charleston, SC, USA. ${ }^{3}$ ános Szentágothai Research Centre \& Department of Pharmacology and Pharmacotherapy,
Medical School, University of Pecs, Ifjúság útja 20, Pécs H-7624, Hungary. ${ }^{4}$ Department of Dentistry, Oral and Maxillofacial Surgery, University of Pecs, Pecs, Hungary. ${ }^{5}$ Department of Oral Rehabilitation, College of Dental Medicine, Medical University of South Carolina, Charleston, SC, USA.

Received: 26 February 2020 Accepted: 29 June 2020

Published online: 06 July 2020

\section{References}

1. McLean JW, von Fraunhofer JA. The estimation of cement film thickness by an in vivo technique. Br Dent J. 1971:131(3):107-11.

2. Fransson B, Oilo G, Gjeitanger R. The fit of metal-ceramic crowns, a clinical study. Dent Mater. 1985:1(5):197-9.

3. Yeo IS, Yang JH, Lee JB. In vitro marginal fit of three all-ceramic crown systems. J Prosthet Dent. 2003:90(5):459-64.

4. Tamac E, Toksavul S, Toman M. Clinical marginal and internal adaptation of CAD/CAM milling, laser sintering, and cast metal ceramic crowns. J Prosthet Dent. 2014;112(4):909-13.

5. Gonzalo E, Suarez MJ, Serrano B, Lozano JF. A comparison of the marginal vertical discrepancies of zirconium and metal ceramic posterior fixed dental prostheses before and after cementation. J Prosthet Dent. 2009:102(6):378-84

6. Siervo S, Pampalone A, Siervo P, Siervo R. Where is the gap? Machinable ceramic systems and conventional laboratory restorations at a glance. Quintessence Int. 1994;25(11):773-9.

7. Bindl A, Mormann WH. Marginal and internal fit of all-ceramic CAD/CAM crown-copings on chamfer preparations. J Oral Rehabil. 2005;32(6):441-7.

8. Quintas AF, Oliveira F, Bottino MA. Vertical marginal discrepancy of ceramic copings with different ceramic materials, finish lines, and luting agents: an in vitro evaluation. J Prosthet Dent. 2004;92(3):250-7.

9. Almasri R, Drago CJ, Siegel SC, Hardigan PC. Volumetric misfit in CAD/CAM and cast implant frameworks: a university laboratory study. J Prosthodont. 2011;20(4):267-74

10. Nagarkar SR, Perdigao J, Seong WJ, Theis-Mahon N. Digital versus conventional impressions for full-coverage restorations: a systematic review and meta-analysis. J Am Dent Assoc. 2018;149(2):139-147 e131.

11. Tsirogiannis $P$, Reissmann DR, Heydecke $G$. Evaluation of the marginal fit of single-unit, complete-coverage ceramic restorations fabricated after digital and conventional impressions: A systematic review and meta-analysis. J Prosthet Dent. 2016;116(3):328-335.e322.

12. Ender A, Zimmermann M, Mehl A. Accuracy of complete- and partial-arch impressions of actual intraoral scanning systems in vitro. Int J Comput Dent. 2019;22(1):11-9.

13. Hack GD, Patzelt SB. Evaluation of the accuracy of six intraoral scanning devices: an in-vitro investigation. ADA Prof Prod Rev. 2015;10(4):5.

14. Mennito AS, Evans ZP, Lauer AW, Patel RB, Ludlow ME, Renne WG. Evaluation of the effect scan pattern has on the trueness and precision of six intraoral digital impression systems. J Esthet Restor Dent. 2018;30(2):113-8.

15. Renne W, Ludlow M, Fryml J, Schurch Z, Mennito A, Kessler R, Lauer A. Evaluation of the accuracy of 7 digital scanners: an in vitro analysis based on 3-dimensional comparisons. J Prosthet Dent. 2017;118(1):36-42.

16. Zimmermann M, Valcanaia A, Neiva G, Mehl A, Fasbinder D. Influence of different CAM strategies on the fit of partial crown restorations: a digital three-dimensional evaluation. Oper Dent. 2018:43(5):530-8.

17. Tsitrou EA, Northeast SE, van Noort R. Evaluation of the marginal fit of three margin designs of resin composite crowns using CAD/CAM. J Dent. 2007; 35(1):68-73.

18. Renne W, McGill ST, Forshee KV, DeFee MR, Mennito AS. Predicting marginal fit of CAD/CAM crowns based on the presence or absence of common preparation errors. J Prosthet Dent. 2012;108(5):310-5.

19. Nakamura T, Dei N, Kojima T, Wakabayashi K. Marginal and internal fit of Cerec 3 CAD/CAM all-ceramic crowns. Int J Prosthodont. 2003;16(3):244-8.

20. Shim JS, Lee JS, Lee JY, Choi YJ, Shin SW, Ryu JJ. Effect of software version and parameter settings on the marginal and internal adaptation of crowns fabricated with the CAD/CAM system. J Appl Oral Sci. 2015;23(5):515-22.

21. Sadid-Zadeh R, Katsavochristou A, Squires T, Simon M. Accuracy of marginal fit and axial wall contour for lithium disilicate crowns fabricated using three digital workflows. J Prosthet Dent. 2020;123(1):121-7.

22. Lee KB, Park CW, Kim KH, Kwon TY. Marginal and internal fit of all-ceramic crowns fabricated with two different CAD/CAM systems. Dent Mater J. 2008 27(3):422-6 
23. Bocklet C, Renne W, Mennito A, Bacro T, Latham J, Evans Z, Ludlow M, Kelly A, Nash J. Effect of scan substrates on accuracy of 7 intraoral digital impression systems using human maxilla model. Orthod Craniofac Res. 2019;22:168-74.

24. Dutton E, Ludlow M, Mennito A, Kelly A, Evans Z, Culp A, Kessler R, Renne $W$. The effect different substrates have on the trueness and precision of eight different intraoral scanners. J Esthet Restor Dent. 2020;32(2):204-18.

25. Flügge TV, Schlager S, Nelson K, Nahles S, Metzger MC. Precision of intraoral digital dental impressions with iTero and extraoral digitization with the iTero and a model scanner. Am J Orthod Dentofac Orthop. 2013;144(3):471-8.

26. Rosenstiel SF, Land MF, Fujimoto J. Contemporary fixed prosthodontics. 4th ed. St. Louis: Mosby/Elsevier; 2006.

27. Shillingburg HT. Fundamentals of fixed prosthodontics. 3rd ed. Chicago: Quintessence Pub. Co.; 1997.

28. Vag J, Nagy Z, Simon B, Mikolicz A, Kover E, Mennito A, Evans Z, Renne W. A novel method for complex three-dimensional evaluation of intraoral scanner accuracy. Int J Comput Dent. 2019;22(3):239-49.

29. Janiszewska-Olszowska J, Tandecka K, Szatkiewicz T, Sporniak-Tutak K, Grocholewicz K. Three-dimensional quantitative analysis of adhesive remnants and enamel loss resulting from debonding orthodontic molar tubes. Head Face Med. 2014;10:37.

30. Dold P, Bone MC, Flohr M, Preuss R, Joyce TJ, Deehan D, Holland J. Validation of an optical system to measure acetabular shell deformation in cadavers. Proc Inst Mech Eng H. 2014;228(8):781-6.

31. Holmes JR, Bayne SC, Holland GA, Sulik WD. Considerations in measurement of marginal fit. J Prosthet Dent. 1989;62(4):405-8.

32. Vaz S, Falkmer T, Passmore AE, Parsons $R$, Andreou P. The case for using the repeatability coefficient when calculating test-retest reliability. PLoS One. 2013;8(9):e73990.

33. Koo TK, Li MY. A guideline of selecting and reporting Intraclass correlation coefficients for reliability research. J Chiropr Med. 2016;15(2):155-63.

34. Bi J, Kuesten C. Intraclass correlation coefficient (ICC): a framework for monitoring and assessing performance of trained sensory panels and panelists. J Sens Stud. 2012;27(5):352-64.

35. Tew GA, Klonizakis M, Crank H, Briers JD, Hodges GJ. Comparison of laser speckle contrast imaging with laser Doppler for assessing microvascular function. Microvasc Res. 2011;82(3):326-32.

36. Shoukri MM, Colak D, Kaya N, Donner A. Comparison of two dependent within subject coefficients of variation to evaluate the reproducibility of measurement devices. BMC Med Res Methodol. 2008:8:24.

37. Euser AM, Dekker FW, le Cessie S. A practical approach to bland-Altman plots and variation coefficients for log transformed variables. J Clin Epidemiol. 2008;61(10):978-82.

38. Bronson MR, Lindquist TJ, Dawson DV. Clinical acceptability of crown margins versus marginal gaps as determined by pre-doctoral students and prosthodontists. J Prosthodont. 2005;14(4):226-32.

39. Rossetti PH, do Valle AL, de Carvalho RM, De Goes MF, Pegoraro LF. Correlation between margin fit and microleakage in complete crowns cemented with three luting agents. J Appl Oral Sci. 2008;16(1):64-9.

40. White $S N$, Ingles $S$, Kipnis V. Influence of marginal opening on microleakage of cemented artificial crowns. J Prosthet Dent. 1994;71(3):257-64.

41. Felton DA, Kanoy BE, Bayne SC, Wirthman GP. Effect of in vivo crown margin discrepancies on periodontal health. J Prosthet Dent. 1991;65(3): 357-64.

42. McLean JW. Polycarboxylate cements. Five years experience in general practice. Br Dent J. 1972;132(1):9-15.

43. Akin A, Toksavul S, Toman M. Clinical marginal and internal adaptation of maxillary anterior single all-ceramic crowns and 2-year randomized controlled clinical trial. J Prosthodont. 2015;24(5):345-50.

44. Fasbinder DJ. Clinical performance of chairside CAD/CAM restorations. J Am Dent Assoc. 2006;137(Suppl):22S-31S.

45. Aziz A, El-Mowafy O, Tenenbaum HC, Lawrence HP, Shokati B. Clinical performance of chairside monolithic lithium disilicate glass-ceramic CADCAM crowns. J Esthet Restor Dent. 2019;31(6):613-9.

46. Roulet JF. Marginal integrity: clinical significance. J Dent. 1994;22(Suppl 1): S9-12.

47. Romeo E, lorio M, Storelli S, Camandona M, Abati S. Marginal adaptation of full-coverage CAD/CAM restorations: in vitro study using a non-destructive method. Minerva Stomatol. 2009;58(3):61-72.

48. Olley RC, Andiappan M, Frost PM. An up to 50-year follow-up of crown and veneer survival in a dental practice. J Prosthet Dent. 2018;119(6):935-41.
49. Stoll R, Sieweke M, Pieper K, Stachniss V, Schulte A. Longevity of cast gold inlays and partial crowns--a retrospective study at a dental school clinic. Clin Oral Investig. 1999;3(2):100-4.

50. May KB, Russell MM, Razzoog ME, Lang BR. Precision of fit: the Procera AllCeram crown. J Prosthet Dent. 1998;80(4):394-404.

51. Naert I, Van der Donck A, Beckers L. Precision of fit and clinical evaluation of all-ceramic full restorations followed between 0.5 and 5 years. J Oral Rehabil. 2005;32(1):51-7.

52. Peroz I, Mitsas T, Erdelt K, Kopsahilis N. Marginal adaptation of lithium disilicate ceramic crowns cemented with three different resin cements. Clin Oral Investig. 2019;23(1):315-20.

53. Meirowitz A, Bitterman Y, Levy S, Mijiritsky E, Dolev E. An in vitro evaluation of marginal fit zirconia crowns fabricated by a CAD-CAM dental laboratory and a milling center. BMC Oral Health. 2019;19(1):103.

54. Alajaji NK, Bardwell D, Finkelman M, Ali A. Micro-CT evaluation of ceramic inlays: comparison of the marginal and internal fit of five and three Axis CAM Systems with a heat press technique. J Esthet Restor Dent. 2017;29(1):49-58.

55. Boeddinghaus M, Breloer ES, Rehmann P, Wostmann B. Accuracy of singletooth restorations based on intraoral digital and conventional impressions in patients. Clin Oral Investig. 2015;19(8):2027-34.

56. Son K, Lee S, Kang SH, Park J, Lee KB, Jeon M, Yun BJ. A comparison study of marginal and internal fit assessment methods for fixed dental prostheses. J Clin Med. 2019;8(6):785.

57. Tabata LF, de Lima Silva TA, de Paula Silveira AC, Ribeiro APD. Marginal and internal fit of CAD-CAM composite resin and ceramic crowns before and after internal adjustment. J Prosthet Dent. 2020;123(3):500-5.

58. Riccitiello F, Amato M, Leone R, Spagnuolo G, Sorrentino R. In vitro evaluation of the marginal fit and internal adaptation of zirconia and Lithium Disilicate single crowns: micro-CT comparison between different manufacturing procedures. Open Dent J. 2018;12:160-72.

59. Saab RC, da Cunha LF, Gonzaga CC, Mushashe AM, Correr GM. Micro-CT analysis of Y-TZP copings made by different CAD/CAM Systems: marginal and internal fit. Int J Dent. 2018;2018:5189767.

60. Groten M, Axmann D, Pröbster L, Weber H. Determination of the minimum number of marginal gap measurements required for practical in-vitro testing. J Prosthet Dent. 2000;83(1):40-9.

61. De Freitas BN, Tonin BSH, Macedo AP, Dos Santos TMP, De Mattos M, Hotta $\mathrm{TH}$, Matsumoto W. Adaptation accuracy of milled lithium disilicate crowns: a 2D and 3D microCT analysis. J Esthet Restor Dent. 2020;32:403-9.

62. Aditya P, Madhav VN, Bhide SV, Aditya A. Marginal discrepancy as affected by selective placement of die-spacer: an in vitro study. J Indian Prosthodont Soc. 2012;12(3):143-8

63. Gressler May L, Kelly JR, Bottino MA, Hill T. Influence of the resin cement thickness on the fatigue failure loads of CAD/CAM feldspathic crowns. Dent Mater. 2015;31(8):895-900.

64. Boening KW, Walter MH, Reppel PD. Non-cast titanium restorations in fixed prosthodontics. J Oral Rehabil. 1992;19(3):281-7.

65. Karlsson S. The fit of Procera titanium crowns. An in vitro and clinical study. Acta Odontol Scand. 1993;51(3):129-34.

66. Gaintantzopoulou MD, El-Damanhoury HM. Effect of preparation depth on the marginal and internal adaptation of computer-aided design/computerassisted manufacture Endocrowns. Oper Dent. 2016;41(6):607-16.

67. Grajower R, Zuberi Y, Lewinstein I. Improving the fit of crowns with die spacers. J Prosthet Dent. 1989;61(5):555-63.

68. Mule SA, Dange SP, Khalikar AN, Vaidya SP. Effect of varying layers of two die spacers on Precementation space of full coverage restorations. J Indian Prosthodont Soc. 2014;14(Suppl 1):67-75.

69. Soriani NC, Leal MB, Paulino SM, Pagnano VO, Bezzon OL. Effect of the use of die spacer on the marginal fit of copings cast in $\mathrm{NiCr}, \mathrm{NiCrBe}$ and commercially pure titanium. Braz Dent J. 2007;18(3):225-30.

70. Fusayama $\mathrm{T}$, Ide $\mathrm{K}$, Hosoda $\mathrm{H}$. Relief of resistance of cement of full cast crowns. J Prosthet Dent. 1964;14(1):95-106.

71. Eames WB, O'Neal SJ, Monteiro J, Miller C, Roan JD Jr, Cohen KS. Techniques to improve the seating of castings. J Am Dent Assoc. 1978;96(3):432-7.

72. Hmaidouch $R$, Neumann P, Mueller WD. Influence of preparation form, luting space setting and cement type on the marginal and internal fit of CAD/CAM crown copings. Int J Comput Dent. 2011;14(3):219-26.

73. Zhang Y, Dudley J. The influence of different cement spaces on the marginal gap of CAD/CAM all-ceramic crowns. Aust Dent J. 2019;64(2): 167-74. 
74. Jorgensen KD, Esbensen AL. The relationship between the film thickness of zinc phosphate cement and the retention of veneer crowns. Acta Odontol Scand. 1968;26(3):169-75.

75. Molin MK, Karlsson SL, Kristiansen MS. Influence of film thickness on joint bend strength of a ceramic/resin composite joint. Dent Mater. 1996;12(4): 245-9.

76. Cekic-Nagas I, Canay S, Sahin E. Bonding of resin core materials to lithium disilicate ceramics: the effect of resin cement film thickness. Int J Prosthodont. 2010;23(5):469-71.

77. Mobilio N, Fasiol A, Mollica F, Catapano S. Effect of different luting agents on the retention of Lithium Disilicate ceramic crowns. Materials (Basel). 2015;8(4):1604-11.

78. May LG, Kelly JR, Bottino MA, Hill T. Effects of cement thickness and bonding on the failure loads of CAD/CAM ceramic crowns: multi-physics FEA modeling and monotonic testing. Dent Mater. 2012;28(8):e99-e109.

79. Sagsoz NP, Yanikoglu N. Evaluation of the fracture resistance of computeraided design/computer-aided manufacturing monolithic crowns prepared in different cement thicknesses. Niger J Clin Pract. 2018;21(4):417-22.

80. Scherrer SS, de Rijk WG, Belser UC, Meyer J-M. Effect of cement film thickness on the fracture resistance of a machinable glass-ceramic. Dent Mater. 1994;10(3):172-7.

81. Beuer F, Schweiger J, Edelhoff D. Digital dentistry: an overview of recent developments for CAD/CAM generated restorations. Br Dent J. 2008;204(9): 505-11

82. Kirsch C, Ender A, Attin T, Mehl A. Trueness of four different milling procedures used in dental CAD/CAM systems. Clin Oral Investig. 2017;21(2): $551-8$.

83. Nedelcu R, Olsson P, Nystrom I, Thor A. Finish line distinctness and accuracy in 7 intraoral scanners versus conventional impression: an in vitro descriptive comparison. BMC Oral Health. 2018;18(1):27.

84. Koch GK, Gallucci GO, Lee SJ. Accuracy in the digital workflow: from data acquisition to the digitally milled cast. J Prosthet Dent. 2016;115(6):749-54

\section{Publisher's Note}

Springer Nature remains neutral with regard to jurisdictional claims in published maps and institutional affiliations.

Ready to submit your research? Choose BMC and benefit from:

- fast, convenient online submission

- thorough peer review by experienced researchers in your field

- rapid publication on acceptance

- support for research data, including large and complex data types

- gold Open Access which fosters wider collaboration and increased citations

- maximum visibility for your research: over $100 \mathrm{M}$ website views per year

At $\mathrm{BMC}$, research is always in progress.

Learn more biomedcentral.com/submissions 